\title{
Causes of changes in carotid intima-media thickness: a literature review
}

\author{
Baoge $\mathrm{Qu}^{1 *}$ and Tao $\mathrm{Qu}^{2}$
}

\begin{abstract}
Atherosclerosis causes significant morbidity and mortality. Carotid intima-media thickness (CIMT) predicts future cardiovascular and ischaemic stroke incidence. CIMT, a measure of atherosclerotic disease, can be reliably determined in vivo by carotid ultrasound. In this review, we determined that CIMT is associated with traditional cardiovascular risk factors such as age, sex, race, smoking, alcohol consumption, habitual endurance exercise, blood pressure, dyslipidemia, dietary patterns, risk-lowering drug therapy, glycemia, hyperuricemia, obesity-related anthropometric parameters, obesity and obesity-related diseases. We also found that CIMT is associated with novel risk factors, including heredity, certain genotypic indices, anthropometric cardiovascular parameters, rheumatoid arthritis, immunological diseases, inflammatory cytokines, lipid peroxidation, anthropometric hemocyte parameters, infectious diseases, vitamin D, matrix metalloproteinases, and other novel factors and diseases. However, the conclusions are inconsonant; the underlying causes of these associations remain to be further explored.
\end{abstract}

Keywords: Ultrasound, Atherosclerosis, Peripheral vessel, Carotid intima-media thickness, Cardiovascular and cerebrovascular diseases, Risk factors

\section{Background}

Atherosclerosis is an important pathologic cause of cardiovascular $(\mathrm{CV})$ and cerebrovascular diseases. Additionally, $\mathrm{CV}$ and cerebrovascular diseases are the leading causes of mortality in humans and can have significant impacts on morbidity. Therefore, the early prevention of $\mathrm{CV}$ and cerebrovascular diseases has become a focus of current research. Preclinical atherosclerosis has been related to higher coronary heart disease and stroke rates. Studies have demonstrated that carotid ultrasonography [1] is more sensitive than the coronary artery calcification score (CACS) for the detection of subclinical atherosclerosis. Hence, carotid intima-media thickness (CIMT) ultrasonography may represent an accessible and reliable method to detect subclinical atherosclerosis [2]. CIMT is significantly increased in patients with existing plaques [3], is a marker of subclinical organ damage and is an independent predictor of $\mathrm{CV}$ and cerebrovascular events. Several studies have reported that

\footnotetext{
* Correspondence: qubaoge@sina.com

${ }^{1}$ Department of Gastroenterology, Taishan Hospital, Taian, Shandong 271000 P. R. China

Full list of author information is available at the end of the article
}

associations exist between CIMT and established risk factors. Thus far, the current concepts of the risk factors of CIMT in the existing literature are not unified. We combined the existing reports to summarize the risk factors of CIMT, including traditional risk factors that have been recognized, such as age, sex, smoking, alcohol consumption, blood pressure (BP), blood fat, blood sugar, lifestyle habits and others; however, the traditional risk factors do not explain all of the risks. A recent study revealed that $>60 \hat{\mathrm{A}} \%$ of CIMT cases were not explained by demographic and traditional CV risk factors, which highlights the need to study novel risk factors [4], which likely represent additional risk factors for carotid atherosclerosis. These novel risk factors refer to recently researched and not yet widely recognized risk factors, such as lifestyle, job pressure, certain diseases, genetic risk factors for certain diseases, and novel environmental, physiologic and pathologic parameters. Therefore, to further understand the factors that influence CIMT associated with traditional $\mathrm{CV}$ risk factors and novel risk factors, we have reviewed the relevant literature from PubMed by searching the keywords: "ultrasound" AND "carotid intima-media thickness" AND "clinical research" 
AND "traditional cardiovascular risk factors" OR "novel risk factors". Identifying novel risk factors associated with CIMT will be helpful for the prevention and treatment of early atherosclerosis.

\section{The associations between CIMT and traditional CV risk factors}

The associations between CIMT and age, sex, race, smoking, alcohol consumption and habitual endurance exercise

Age, sex, race, smoking and alcohol consumption play important roles in atherosclerosis. CIMT may be a valuable marker for $\mathrm{CV}$ risk in adults aged $<45 \hat{\mathrm{A}}$ years who are not yet eligible for standard CV risk screening [5]. Gestational age was not found to affect CIMT [6], and age-related increases in CIMT correlated with a decline in cardiac diastolic function only in women [7]. CIMT was similar between healthy South Asian and European men [8]. Although males exhibited a significantly greater CIMT than females, the difference failed to reach statistical significance after adjusting for carotid diameter [9]. However, sex differences in the associations between childhood and adulthood risk factors and subclinical atherosclerosis were found [10]. Additionally, CIMT was positively associated with smoking [11] and alcohol consumption in men [12]. However, an opposite finding showed that alcohol consumption might also be beneficial for CIMT in men and that the effect of alcohol on CIMT might be mediated by lipid factors [13]. Habitual endurance exercises, particularly aerobic exercise, are important measures of atherosclerosis prevention. Previous studies have revealed that $8 \hat{\mathrm{A}}$ weeks [14] or 6 months [15] of aerobic exercise training might significantly improve the vascular structure and function in African Americans. The weight-adjusted maximal oxygen uptake capacity inversely correlates with CIMT [16]. However, although habitual endurance exercise might improve CV risk profiles, it does not reduce the magnitude of carotid atherosclerosis associated with age and CV risk factors [17]. Hence, determining the effects of different exercises on CIMT requires further studies.

\section{The associations between CIMT and BP}

High BP has been recognized as an important risk factor for $\mathrm{CV}$ and cerebrovascular diseases. However, the associations between CIMT and different types of abnormal $\mathrm{BP}$ in different populations remain unknown. High BP is a major determinant of CIMT [18]. Systolic BP [19-21], diastolic BP (DBP) $[10,22]$, higher pulse pressure (PP) $[6,21]$, daytime BP [23], persistently elevated BP from childhood to adulthood [24], within-visit DBP variability in the normotensive population [25] and systolic BP variability (SBPV) [26] were also found to be positively associated with CIMT. SBP [27] appears to be a main pathological mechanism that indirectly affects CIMT through the hemodynamic pathway. This risk was reduced if $\mathrm{BP}$ that was elevated during childhood was resolved by adulthood [24]. Moreover, the correlation between BP variability (BPV) and left common carotid artery-intima-media thickness/number of plaques is stronger than right common carotid artery-intima-media thickness/number of plaques [26]. The increase in CIMT in Congolese hypertensive subjects was identified as a marker of arterial remodeling associated with a long history of uncontrolled hypertension rather than of early atherosclerosis [28]. In a sample of hypertensive African men, CIMT was negatively associated with glutathione (GSH) levels [29], suggesting that CIMT might contribute to the attenuation of GSH levels in the development of subclinical atherosclerosis. In summary, all types of hypertension are major causes of preclinical atherosclerosis. Thus, to achieve prevention of early atherosclerosis, proper measures should be taken to control hypertension.

\section{The associations between CIMT and dyslipidemia, dietary patterns and risk-lowering drug therapy}

Healthy and unhealthy lifestyle changes during young adulthood are associated with decreased and increased risks, respectively, for subclinical atherosclerosis in middle age [30]. Dyslipidemia is an important factor for atherosclerosis that has been shown to be associated with CIMT [18]. Regression analysis demonstrated that the mean and maximum CIMT (CIMT[max]) are independently influenced by age, blood creatinine levels and nonhigh density lipoprotein (HDL) cholesterol levels [22]. In particular, patients with familial hypercholesterolemia $(\mathrm{FH})$ are at increased risk of premature $\mathrm{CV}$ disease. Hypercholesterolemic children [31] and patients with FH [32] exhibited significantly higher CIMT. Results of CIMT meta-analysis strengthen the evidence of early atherosclerotic development in children with $\mathrm{FH}$. Circulating low-density lipoprotein (LDL-C) concentrations were associated with CIMT [33, 34], and high levels of oxidized LDL (OxLDL) were significantly associated with progression and increased levels of CIMT [35-37]. Low levels of HDL cholesterol or relative levels of the HDL $3 \mathrm{~b}$ subclasses and changes in the proportion of small HDL particles were significantly associated with an increased in CIMT $[20,38]$ and with the presence of carotid plaques [39]. Furthermore, among women, IMT $(\max )$ was significantly negative correlated to HDL cholesterol [40]. In the statin group, HDL cholesterol levels were associated with CIMT; in the combined therapy group, HDL cholesterol levels were the only significant correlate of CIMT [41]. Apoliproproteins are also important risk factors for atherosclerosis. Among them, apolipoprotein $\mathrm{B}(\mathrm{apoB})$ [33] and $\mathrm{ApoB} / \mathrm{ApoA} 1$ [42] were significantly positively associated with CIMT, and the 
absence or very low levels of erythrocyte-bound apoB was associated with clinical and subclinical atherosclerosis [43]. In contrast, other studies revealed that ApoE genotypes and CIMT were not associated [44] and that ApoA1 has an inverse association with CIMT [42]. Therefore, whether changes in dietary patterns affect the risk of early atherosclerosis remains under debate. One study did not find an association between dietary patterns and IMT or plaques [45], and high versus low protein intake in infancy did not influence CIMT at $5 \hat{\mathrm{A}}$ years [44]. However, several studies have demonstrated that a Mediterranean diet has a protective effect on the CV system because lower adherence to a Mediterranean diet was shown to increase the risk of subclinical atherosclerosis [46]. Additionally, 12Â months of Mediterranean diet intervention caused a significant reduction in CIMT [31]. Interventions to lower LDL cholesterol from the suboptimal to the optimal range were shown to have potentially significant benefits to firefighters [34]. Atorvastatin [47], rosuvastatin [48] and fuvastatin [49] treatments slowed or reduced the progression of CIMT; intensive lipid lowering and antihypertensive therapy along with a reduction in central fat [50] may be considered a mandatory treatment strategy in young patients with FH to prevent atherosclerosis and to increase arterial stiffness. In men with $\mathrm{CHD}$ and high levels of $\mathrm{Lp}(\mathrm{a})$, atorvastatin use [51] results in an average $0.06 \hat{\mathrm{A}} \mathrm{mm}$ decrease in CIMT over $6 \hat{\mathrm{A}}$ months. Adequate statin treatment [52] might delay carotid atherosclerosis in $\mathrm{FH}$ independent of Lp(a) levels. Hence, CIMT was associated with dyslipidemia and dysapoliproprotein but was not associated with protein intake. Therefore, intensive lipidlowering therapy might be used to reduce the progression of CIMT in high-risk patients.

\section{The associations between CIMT and glycemia and hyperuricemia}

Glycemia and hyperuricemia are also important risk factors for atherosclerosis-related $\mathrm{CV}$ and cerebrovascular diseases. The glycemic status is associated with all grades of carotid atherosclerosis, from early signs, as demonstrated by the IMT; to intermediate degrees, as demonstrated by the presence of carotid plaques; to advance atherosclerosis, as established by the presence of carotid stenosis [53]. Glycemia, including type 2 diabetes mellitus (T2DM) and impaired fasting glucose (IFG) [54], is a major independent determinant of CIMT in hyperglycemic patients. Insulin levels, the HOMA-IR index, total IGF-1 levels [55] and increased insulin resistance [56] are positively associated with CIMT; simultaneously, insulin resistance in obese adolescents [57] can impair changes in CIMT and can lead to the early development of atherosclerosis. Lower hemoglobin A1c levels [58] were also identified as a significant risk factor for carotid atherosclerosis in rural community-dwelling elderly Japanese men. Low levels of plasma obestatin might be related to early arteriosclerosis in patients with T2DM via increasing CIMT [59], considering that the elevated plasma obestatin levels might protect T2DM patients against carotid atherosclerosis to some extent. Despite reproducing the association between CIMT level and vascular risk in subjects with diabetes, no association between CIMT change and vascular risk was found [60]. However, in patients with T2DM, a 6-month intensive lifestyle modification intervention might result in improved glycemic control and decreased progression of CIMT [61]. Additionally, hyperuricemia is an independent risk factor for $\mathrm{CV}$ and cerebrovascular diseases. Hyperuricemia was inversely associated with subclinical carotid atherosclerosis in men; however, hyperuricemiarelated renal impairment was a significant marker of subclinical carotid atherosclerosis in both men and women [62]. Therefore, a timely intervention for glycemia and hyperuricemia may slow the occurrence of early arteriosclerosis. This timeliness should be a primary focus for clinicians.

\section{The associations between CIMT, obesity-related anthropometric parameters, obesity and \\ obesity-related diseases}

Obesity-related anthropometric parameters, obesity and obesity-related diseases, including nonalcoholic fatty liver disease (NAFLD), alcoholic fatty liver disease (AFLD) and polycystic ovary syndrome (PCOS), have been reported to be associated with increased $\mathrm{CV}$ and cerebrovascular risks. However, the conclusions of the studies in the literature are inconsistent.

\section{The associations between CIMT and obesity-related anthropometric parameters}

Numerous obesity-related anthropometric parameters are used for evaluating the associations between obesity and atherosclerosis-related diseases. Studies have shown that higher CIMT correlated with obesity-related anthropometric parameters, including body mass index (BMI) [18, 63], waist circumference [18], waist-to-hip ratio (WHR) [39, 51] and WHtT [39]. Additionally, the associations between CIMT and fat distribution remain unknown. Visceral adipose tissue (VAT) thickness [64, 65], but not subcutaneous fat thickness [65], was associated with IMT in men and patients requiring peritoneal dialysis. Increased epicardial fat volume [66, 67] and peri-aortic root fat (PARF) [68] were shown to be independent risk factors of increased CIMT. However, a contradictory study [69] suggested that CIMT lacked a relationship with visceral obesity. Thus, prospective studies are needed to further determine the associations 
between CIMT and visceral obesity. Additionally, recent research has demonstrated that the mean CIMT varied across obesity phenotypes [59]; a higher CIMT value and positive associations with carotid plaque and carotid atherosclerosis were observed in only the metabolically abnormal obese subtype [70]. These contradictory findings [71] suggested that obesity does not affect vascular parameters related to early atherosclerosis, including CIMT in women with minor CV risk factors. Further research studies are warranted to identify the correlation between different fat distributions and CIMT.

\section{The associations between CIMT and obese and obesity-related diseases}

Recent studies have suggested that overweight, obese and obesity-related diseases, including NAFLD, AFLD and PCOS, are associated with CIMT. Overweight, obese and morbidly obese patients exhibit similar CIMT and small artery reactivity index values [72]. Patients with NAFLD [35, 73-75] and AFLD [35, 76] had significantly increased CIMT, and the association between NAFLD and subclinical atherosclerosis was independent of traditional risk factors [75]. ALD may also promote the premature increase in CIMT [76] via mechanisms that might include insulin resistance [77] and abnormal liver function, including ALT [78, 79] and GGT [78], in patients with NAFLD and NASH. Age and metabolic factors are also associated with CIM thickening in patients with ALD. PCOS is a common gynecological disease in women, and independent of obesity, patients with PCOS may present with increased CIMT as a direct result of androgen excess [80], suggesting that hyperandrogenism might increase atherosclerosis and CV risks. However, the findings of another study [71] did not support the above conclusions. Therefore, the precise relationships between CIMT and NAFLD, AFLD, and PCOS require further study.

\section{The associations between CIMT and novel risk factors}

The associations between CIMT and heredity and certain genotypic indices

Heredity and genetics play important roles in atherosclerosis. However, whether CIMT is associated with heredity and certain genotypic indices remains unknown. One study suggested that a different set of genes influences variation in CIMT and waist circumference [81]. Certain genetic loci that are determinants of human lung function also influence CIMT and CAD susceptibility [82]. The strongest association was reported between the rate of telomere shortening in adults between 53 and 60-64 years and CIMT in adults 60 to $64 \hat{A}$ years of age [83]. However, the chromosome 9p21 locus does not influence CAD risk through a mechanism that also affects CIMT or that induces early changes in flow-mediated dilatation (FMD) [84]. The haptoglobin (Hp) 2-2 genotype is a significant predictor of premature atherosclerosis and is associated with increased CIMT in children with beta-thalassemia major [85]. Singlenucleotide polymorphisms (SNPs) in 7-dehydrocholesterol reductase/NAD synthetase-1 interacted with type 2 diabetes to significantly influence the progression of CIMT independent of 25(OH)D levels and established risk factors [86]. However, no significant associations were identified between the genotype at any of the SNPs and CIMT in 846 individuals with acceptable measurements [87]. Additionally, humans with the Osteopontin â"66 TT genotype, particularly those without MetS, exhibit thicker CIM [88]. Hence, the associations between CIMT and heredity require further exploration to search for better etiological treatment.

\section{The associations between CIMT and anthropometric CV parameters}

Recent studies have reported that certain cardiac- and artery-related changes may be associated with CIMT. These changes are important complications of T2DM. Studies have revealed that increased CIMT is associated with a high occurrence of cardiac autonomic neuropathy (CAN) [89], the level of coronary artery calcification (CAC) [90] and the coronary SYNTAX score [91]. However, coronary artery disease (CAD) variants were not found to be associated with CIMT and did not appear to mediate the risk of atherothrombosis through known risk factors [90]. Additionally, impaired FMD under various statuses and diseases might led to thicker CIM [78, 92, 93]. Their exact mechanism remains unknown and needs to be further studied.

\section{The associations between CIMT and rheumatoid arthritis (RA) and immunological diseases}

Growing evidence has demonstrated that patients with RA, Behcet disease (BD), systemic lupus erythematosus (SLE), primary SjÃgren syndrome, and psoriatic arthritis (PsA) have a higher risk for atherosclerosis and are associated with enhanced CV risk and subclinical vascular disease. RA is associated with an elevated risk of cardiovascular disease (CVD) [94] events and subclinical atherosclerosis [94, 95]. However, a contradictory study reported that RA does not result in CIM thickening [45]. Recent quantities clinical observations have confirmed that RA is associated with increased CIMT [96-99]. The mechanisms of RA-related CIM thickening included increased levels of Ox-LDL) [100, 101], vWF activity [102], serum mannose-binding lectin [103], and PWV [104] as well as increased levels of inflammation markers [99, 102] such as IL-17 [105], and CRP [106] and lower levels of $\hat{I}^{2}$-carotene [101], vitamin D, CD34+ cells 
$[100,104]$ and NO [101]. Psoriasis is associated with increased mean CIMT [107] and may increase the burden of subclinical atherosclerosis $[107,106]$. More severe subclinical atherosclerosis was observed in patients with PsA [108] compared with patients with cutaneous psoriasis without arthritis (PsC). The causes of atherosclerosis in PsA include markers of accelerated atherosclerosis such as ox-LDLs and NO [101] as well as endothelial dysfunction [106], PsA disease duration, more severe skin disease and increased inflammatory markers; however, atherosclerosis in PsA was not associated with traditional CV risk factors [108]. Furthermore, increased CIMT was associated with juvenile idiopathic arthritis [109], systemic lupus erythematosus [110], and BD [111]. Their mechanisms involved elevated myeloperoxidase levels in juvenile idiopathic arthritis [109], circulating levels of OxLDL and the \% of LDL in systemic lupus erythematosus [110] and impaired FMD in BD [111]. Multivariate model analysis [112] showed that primary SjÃ gren syndrome (SS) might be an independent risk factor for arterial wall thickening when traditional risk factors for CVD were controlled. Another contradictory study [113] revealed no significant difference in CIMT between patients with primary SS and control patients. Additionally, a recent study found that euthyroid premenopausal women with autoimmune thyroiditis [114] and allergic predisposition in early childhood [115] might present significantly increased CIMT. Hence, rheumatoid immunological diseases were related to CIM thickening, and future prospective studies should account for the roles and mechanisms of the above diseases in the progression of atherosclerosis, and standard control and treatment of these diseases so that subclinical atherosclerosis can be prevented as soon as possible.

\section{The associations among CIMT and inflammatory cytokines, lipid peroxidation, anthropometric hemocyte parameters and infectious diseases}

Inflammation and lipid peroxidation may play important roles in the development of atherosclerosis. However, whether immunological parameters, inflammatory cytokines, and lipid peroxidation influence CIMT remains unknown. Inflammatory cytokines such as CRP $[43,116]$ and lipid peroxidation levels [117] correlated with increases in CIMT. However, another study showed that the distributions of MnSOD, GSTM1 and GSTP1 genotypes according to CIMT, plaque type or plaque score did not significantly differ [118]. The findings of our recent study indicated that the increase in CIMT was not associated with cytokine profiles, oxidative balance or immune responses in patients with ALD [76]. Further research is needed to explore the potential associations between CIMT and inflammation and lipid peroxidation.

Leukocyte count and the neutrophil-to-lymphocyte ratio may be used as diagnostic and prognostic indicators of carotid atherosclerosis. Recent studies on anthropometric hemocyte parameters revealed that leukocytes play an independent role in early arterial damage and that these cells may reflect subclinical disease [119]. The neutrophilto-lymphocyte ratio positively and moderately correlated with CIMT in an entire study population [120]. Because the above parameters are convenient and practical, they may be used to evaluate the possibility of infection-related CIM thickening.

The associations between CIMT and certain infectious diseases have been a focus of clinical studies. A preliminary study demonstrated that treated HIV infection is a risk factor for subclinical atherosclerosis in older individuals [42]. However, in a predominantly female HIVinfected population in South Africa [121], CIMT values were considerably high and were associated with $\mathrm{CV}$ risk factors rather than HIV-related factors. Another study supports this viewpoint: old age, longer protease inhibitor exposure, and impaired fasting glucose were independent factors associated with common CIMT in a population living with HIV [122]. Our previous study [123] indicated that either $H$. pylori infection with chronic alcohol use or chronic alcohol use alone could cause a significant increase in CIMT. Additionally, tooth loss and long-term periodontitis were related to subclinical atherosclerosis in men but not in women [124]. Because only a few studies have examined the association of inflammatory cytokines, lipid peroxidation, anthropometric hemocyte parameters and infectious diseases with CIMT, these parameters should be a focus of further studies with larger samples for verification of these findings.

\section{The associations among CIMT and socioeconomic position (SEP) and job stress}

Few studies have shown that CIMT, SEP, and job stress are associated. However, these studies lack consistent conclusions. Present studies have revealed that job strain was related to increased CIMT in valine (Val)/Val carriers [125], adulthood [126] and its early nonsymptomatic stages in men [127]. Job strain appears to increase the risk of preclinical atherosclerosis. A catechol-Omethyltransferase genotype [125], a lack of leadership (a type A behavior component) [126], and an increase in hyperintense spots may explain the link between job strain and cerebrovascular disease [128]. Additionally, CIMT was associated with adult SEP [129] and shift work [130]. However, high-strain jobs and low job control were not associated with IMT independent of SEP; job stress did not explain the association between life course SEP and CIMT [129]. High job demands, interacting synergistically with low decision latitude, did not result in the development of carotid atherosclerosis in 
men or in women [131]. The mechanisms of these associations are unclear. Thus, we should strengthen the studies on associations between CIMT and SEP and job stress to take appropriate measures for early prevention and treatment of atherosclerosis.

\section{The associations between CIMT and vitamin D}

Little is known regarding the association between vitamin D and CIMT. The studies regarding an association between serum vitamin D and CVD risk have presented inconsistent results. Recently, several studies have shown that low serum 25-hydroxyvitamin D3 (25(OH)D) levels in childhood were associated with increased CIMT in adulthood [132] and that subjects with serum 25(OH)D â\% ¥20Â $\mathrm{ng} / \mathrm{mL}$ had less mean-max CIMT progression following $3 \hat{A}$ years of atorvastatin treatment, suggesting that underlying vitamin $\mathrm{D}$ deficiency may be involved in the response to atorvastatin in atherosclerosis prevention [133]. Hence, early application of $25(\mathrm{OH}) \mathrm{D}$ or coupling with oral lipid-lowering drugs such as statins may be helpful for preventing subclinical atherosclerosis. In contrast, serum levels of 25(OH)D were not independently associated with CVD risk factors [134] or CIMT [123, 135, 136]. However, increased serum $25(\mathrm{OH}) \mathrm{D}$ may predict subclinical atherosclerosis in nonsmokers [137]. Hence, the majority of the present studies do not support a protective effect of vitamin D against subclinical atherosclerosis. More studies are needed to explore whether $25(\mathrm{OH}) \mathrm{D}$ may affect the progression of atherosclerosis and the roles of $25(\mathrm{OH}) \mathrm{D}$ supplementation on the atherosclerotic process.

\section{The associations between CIMT and matrix metalloproteinases (MMPs)}

Evidence suggests that MMPs may play an important role in atherosclerosis and be promising new therapeutic targets for treating subclinical atherosclerosis. Higher serum MMP-8 [37], MMP-9 [138, 139], TIMP-1 [138], MMP-9/TIMP-1 [138] and MMP-10 [140] levels were associated with increased CIMT. Hence, the above circulating MMP levels may be useful for identifying subclinical atherosclerosis. In summary, the roles of MMPs in atherosclerosis should be further examined in clinical studies for possible clinical application.

\section{The associations between CIMT and other novel factors and diseases}

Recent studies have found that other novel factors and diseases such as hepatorenal function, microalbuminuria, low muscular strength, $\mathrm{O} 3$, beta-thalassemia minor, growth hormone deficiency and normal-tension glaucoma have certain relations to CIMT. Several studies have revealed that increased serum ALT levels (even high-normal levels) were associated with markers of
CVD [51]. However, a study with opposing results reported that age-adjusted CIMT values did not differ according to GGT levels in males or females [53]. Microalbuminuria correlated with CIMT [141, 142], and muscular strength was inversely and independently associated with CIMT [92]. Childhood exposure to O3 may be a novel risk factor for CIMT in a healthy population of college students [143]. Additionally, higher CIMT was associated with the development of chronic kidney disease [144], growth hormone deficiency [145], betathalassemia minor [146], preeclampsia [142] and menopause transition [147]. However, recent studies could not show associations of elevated parathyroid hormone (PTH) concentrations [136] and normal-tension glaucoma [48] with altered CIMT. Therefore, the associations between CIMT and the above causes require further verification.

\section{Conclusions}

This review of the recent literature presents preliminary evidence of certain associations between CIMT and traditional and novel CV risk factors, showing that CIMT is a good clinical predictor of early atherosclerosis, and that CIMT measurement is convenient, simple and practical. However, the majority of studies to date were retrospective, and the lack of prospective large-scale studies and of a unified measurement method used by clinical researchers limited our analysis. Determining which CIMT value (maximum CIMT, mean CIMT, minimum CIMT, left or right common carotid artery) is obviously associated with early atherosclerosis is necessary. These findings remind us that early prevention of atherosclerosis should start from infancy to enable detection of an abnormal state of health. Further studies focusing on both traditional and novel CV risk factors are needed. Because the human body is a unified whole, all types of abnormal states of health are likely to cause harm to the human body, including the blood vessel system. Hence, we should pay more attention to the health status of the human body, and to protect blood vessels and prevent early atherosclerosis, we should strengthen the treatment of abnormal states of health and diseases.

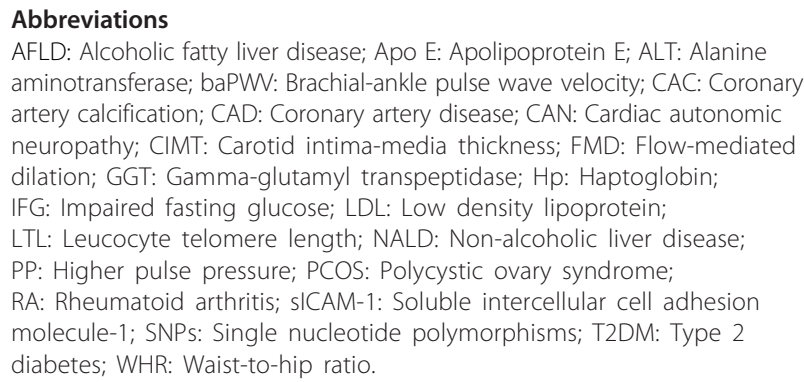
aminotransferase; baPW: Brachial-ankle pulse wave velocity; CAC: Coronary artery calcification; CAD: Coronary artery disease; CAN: Cardiac autonomic neuropathy; CIMT: Carotid intima-media thickness; FMD: Flow-mediated dilation; GGT: Gamma-glutamyl transpeptidase; Hp: Haptoglobin; IFG: Impaired fasting glucose; LDL: Low density lipoprotein; LTL: Leucocyte telomere length; NALD: Non-alcoholic liver disease; PP: Higher pulse pressure; PCOS: Polycystic ovary syndrome; RA: Rheumatoid arthritis; sICAM-1: Soluble intercellular cell adhesion molecule-1; SNPs: Single nucleotide polymorphisms; T2DM: Type 2 diabetes; WHR: Waist-to-hip ratio.

Competing interests

All of the authors declare that they have no conflicts of interest. 


\section{Authors' contribution}

Literatures involved in this manuscript were reviewed and re-writed by QB and QT. Both authors read and approved the final manuscript.

\section{Financial support}

This research was supported by a grant from the Technology Bureau of Taian City (No. 20123039) and by the Health Department of Shandong Province (No. 2013BJYB26)

\section{Author details}

'Department of Gastroenterology, Taishan Hospital, Taian, Shandong 271000, P. R. China. ${ }^{2}$ Zhuhai Campus of Zunyi Medical College, Zhuhai, Guangdong 519041, P. R. China.

Received: 24 November 2015 Accepted: 9 December 2015 Published online: 15 December 2015

\section{References}

1. Corrales A, Parra JA, GonzÃ Alez-Juanatey C, Rueda-Gotor J, Blanco R, Llorca J, et al. Cardiovascular risk stratification in rheumatic diseases: carotid ultrasound is more sensitive than Coronary Artery Calcification Score to detect subclinical atherosclerosis in patients with rheumatoid arthritis. Ann Rheum Dis. 2013;72(11):1764-7170.

2. Onut R, Balanescu AP, Constantinescu D, Calmac L, Marinescu M, Dorobantu PM. Imaging atherosclerosis by carotid intima-media thickness in vivo: how to, where and in whom? Maedica (Buchar). 2012:7(2):153-62.

3. Morris EP, Denton ER, Robinson J, MacDonald LM, Rymer JM. High resolution ultrasound assessment of the carotid artery: its relevance in postmenopausal women and the effects of tibolone on carotid artery ultrastructure. Climacteric. 1999:2(1):13-20.

4. Santos IS, Alencar AP, Rundek T, Goulart AC, Barreto SM, Pereira AC, et al. Low impact of traditional risk factors on carotid intima-media thickness: the ELSA-Brasil cohort. Arterioscler Thromb Vasc Biol. 2015;35(9):2054-9.

5. Eikendal AL, Groenewegen KA, Anderson TJ, Britton AR, Engstr $\tilde{A} \boldsymbol{m} m \mathrm{~m}$, Evans GW, et al. Common carotid intima-media thickness relates to cardiovascular events in adults aged $<45 \hat{A}$ years. Hypertension. 2015;65(4):707-13.

6. Kerkhof GF, Breukhoven PE, Leunissen RW, Willemsen RH, Hokken-Koelega AC. Does preterm birth influence cardiovascular risk in early adulthood? J Pediatr. 2012;161(3):390-6.

7. Han L, Bai X, Lin H, Sun X, Chen X. Gender differences in the relationship between age-related carotid intima-media thickness and cardiac diastolic function in a healthy Chinese population. J Card Fail. 2013;19(5):325-32.

8. Ghouri N, Purves D, Deans KA, Logan G, McConnachie A, Wilson J, et al. An investigation of two-dimensional ultrasound carotid plaque presence and intima media thickness in middle-aged South Asian and European men living in the United Kingdom. PLoS One. 2015;10(4), e0123317. doi:10.1371/journal.pone.0123317.eCollection2015.

9. Dengel DR, Jacobs DR, Steinberger J, Moran AM, Sinaiko AR. Gender differences in vascular function and insulin sensitivity in young adults. Clin Sci (Lond). 2011;120(4):153-60.

10. Ceponiene I, Klumbiene J, Tamuleviciute-Prasciene E, Motiejunaite J, Sakyte E, Ceponis J, et al. Associations between risk factors in childhood (12-13 years) and adulthood (48-49 years) and subclinical atherosclerosis: the Kaunas Cardiovascular Risk Cohort Study. BMC Cardiovasc Disord. 2015;15: 89. doi:10.1186/s12872-015-0087-0.

11. Kawase Ishihara K, Kokubo Y, Yokota C, Hida E, Miyata T, Toyoda K, et al. Effect of plasma fibrinogen, high-sensitive $\mathrm{C}$-reactive protein, and cigarette smoking on carotid atherosclerosis: the Suita study. J Stroke Cerebrovasc Dis. 2015. doi:10.1016/j.jstrokecerebrovasdis.2015.06.039 [Epub ahead of print].

12. Zyriax BC, Lau K, KIÃahn T, Boeing H, VÃ I/zke H, Windler E. Association between alcohol consumption and carotid intima-media thickness in a healthy population: data of the STRATEGY study (Stress, Atherosclerosis and ECG Study). Eur J Clin Nutr. 2010;64:1199-206.

13. Kim MK, Shin J, Kweon SS, Shin DH, Lee YH, Chun BY, et al. Harmful and beneficial relationships between alcohol consumption and subclinical atherosclerosis. Nutr Metab Cardiovasc Dis. 2014;24(7):767-76.

14 Ranadive SM, Yan $H$, Lane AD, Kappus RM, Cook MD, Sun P, et al. Aerobic exercise training and arterial changes in African-Americans versus Caucasians. Med Sci Sports Exerc. 2015 Jul 29. [Epub ahead of print]
15. Feairheller DL, Diaz KM, Kashem MA, Thakkar SR, Veerabhadrappa P, Sturgeon KM, et al. Effects of moderate aerobic exercise training on vascular health and blood pressure in African Americans. J Clin Hypertens (Greenwich). 2014:16(7):504-10.

16. HÃagg U, Wandt B, Bergstrã Am G, Volkmann R, Gan L. Physical exercise capacity is associated with coronary and peripheral vascular function in healthy young adults. Am J Physiol Heart Circ Physiol. 2005;289:H1627-34. doi:10.1152/ajpheart.00135.2005. First published June 3, 2005.

17. Taylor BA, Zaleski AL, Capizzi JA, Ballard KD, Troyanos C, Baggish AL, et al. Influence of chronic exercise on carotid atherosclerosis in marathon runners. BMJ Open. 2014:4(2), e004498. doi:10.1136/bmjopen-2013-004498.

18. Acevedo M, KrÄamer V, Tagle R, Arnaiz P, CorbalÄjn R, BerrÃos X, et al. Cardiovascular risk factors among young subjects with high carotid intima media thickness. Rev Med Chil. 2011;139(10):1322-9.

19. Breton CV, Wang X, Mack WJ, Berhane K, Lopez M, Islam TS, et al. Carotid artery intima-media thickness in college students: race/ethnicity matters. Atherosclerosis. 2011;217(2):441-6.

20. Ayer JG, Harmer JA, Nakhla S, Xuan W, Ng MK, Raitakari OT, et al. HDLcholesterol, blood pressure, and asymmetric dimethylarginine are significantly associated with arterial wall thickness in children. Arterioscler Thromb Vasc Biol. 2009:29(6):943-9.

21. Geraci G, MulÃ" G, Costanza G, Mogavero M, Geraci C, Cottone S. Relationship between carotid atherosclerosis and pulse pressure with renal hemodynamics in hypertensive patients. Am J Hypertens. 2015 Aug 1. [Epub ahead of print]

22. Bosevski M. Carotid IMT, in type 2 diabetic patients: a survey on factors of influence. Prilozi. 2011;32(2):289-97.

23. Lee SH, Kim JH, Kang MJ, Lee YA, Won Yang S, Shin CH. Implications of nocturnal hypertension in children and adolescents with type 1 diabetes. Diabetes Care. 2011;34(10):2180-5.

24. Juhola J, Magnussen CG, Berenson GS, Venn A, Burns TL, Sabin MA, et al. Combined effects of child and adult elevated blood pressure on subclinical atherosclerosis: the International Childhood Cardiovascular Cohort Consortium. Circulation. 2013;128(3):217-24.

25. Li Y, Liu J, Wang W, Zhao D. The association between within-visit blood pressure variability and carotid artery atherosclerosis in general population. PLoS One. 2014:9(5), e97760. doi:10.1371/journal.pone.0097760. eCollection2014.

26. Chen $Y$, Xiong $H$, Wu D, Pirbhulal S, Tian X, Zhang R, et al. Relationship of short-term blood pressure variability with carotid intima-media thickness in hypertensive patients. Biomed Eng Online. 2015;14:71. doi:10.1186/s12938015-0059-8

27. Dratva J, Caviezel S, Schaffner E, Zemp E, DeGroot E, Schmidt-TrucksÃass A, et al. Early detection of subjects at risk for vascular remodelling-results from the Swiss population-based study SAPALDIA. Swiss Med Wkly. 2014;144: w14052.

28. Bianga Katchunga P, Mongane Irenge J, Canwa R, Matabaro A, Nsimire S, Kabunga Q. Carotid intima-media thickness in the Congolese hypertensive in South Kivu. Ann Cardiol Angeiol (Paris). 2014. doi:10.1016/j.ancard.2014.11 001 [Epub ahead of print].

29. Schutte R, Schutte $A E$, Huisman HW, van Rooyen JM, Malan NT, PÃ@ter S, et al. Blood glutathione and subclinical atherosclerosis in African men: the SABPA Study. Am J Hypertens. 2009;22(11):1154-9.

30. Spring B, Moller AC, Colangelo LA, Siddique J, Roehrig M, Daviglus ML, et al. Healthy lifestyle change and subclinical atherosclerosis in young adults: Coronary Artery Risk Development in Young Adults (CARDIA) study. Circulation. 2014;130(1):10-7.

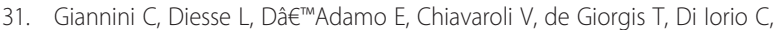
et al. Influence of the Mediterranean diet on carotid intima-media thickness in hypercholesterolaemic children: a 12-month intervention study. Nutr Metab Cardiovasc Dis. 2014;24(1):75-82.

32. Narverud I, Retterst̃̃ II K, Iversen PO, Halvorsen B, Ueland T, Ulven SM, et al. Markers of atherosclerotic development in children with familia hypercholesterolemia: a literature review. Atherosclerosis. 2014;235:299-309.

33. Dessein PH, Woodiwiss AJ, Norton GR, Solomon A. Rheumatoid arthritis is associated with reduced adiposity but not with unfavorable major cardiovascular risk factor profiles and enhanced carotid atherosclerosis in black Africans from a developing population: a cross-sectional study. Arthritis Res Ther. 2013:15(4):R96. doi:10:1186/ar4276.

34. Burgess $J \mathrm{~L}$, Kurzius-Spencer M, Gerkin RD, Fleming JL, Peate WF, Allison M. Risk factors for subclinical atherosclerosis in firefighters. J Occup Environ Med. 2012;54(3):328-35. 
35. Lopes-Virella MF, Hunt KJ, Baker NL, Lachin J, Nathan DM, Virella G, et al. Levels of oxidized LDL and advanced glycation end products-modified LDL in circulating immune complexes are strongly associated with increased levels of carotid intima-media thickness and its progression in type 1 diabetes. Diabetes. 2011;60(2):582-9.

36. Hunt KJ, Baker N, Cleary P, Backlund JY, Lyons T, Jenkins A, et al. Oxidized $L D L$ and $A G E-L D L$ in circulating immune complexes strongly predict progression of carotid artery IMT in type 1 diabetes. Atherosclerosis. 2013; 231(2):315-22

37. Paim LR, Schreiber R, Matos-Souza JR, Silva AA, Campos LF, Azevedo ER, et al. Oxidized low-density lipoprotein, matrix-metalloproteinase-8 and carotid atherosclerosis in spinal cord injured subjects. Atherosclerosis. 2013; 231:341e345.

38. Kim CS, Kim SK, Araneta MRG, Lee EJ, Barrett-Connor E, Huh KB. Can increased visceral adiposity without body weight changes accelerate carotid atherosclerosis in South Korean participants with type 2 diabetes? J Diabetes Complications 2015;29(8):1085-1091. http://dx.doi. org/10.1016/j.jdiacomp.2015.06.007. Epub 2015 Jun 19.

39. Ge W, Parvez F, Wu F, Islam T, Ahmed A, Shaheen I, et al. Association between anthropometric measures of obesity and subclinical atherosclerosis in Bangladesh. Atherosclerosis. 2014;232(1):234-41.

40. Hurwitz Eller N, NetterstrÃ $m$ m B. The intima media thickness and coronary risk factors. Int Angiol. 2001;20(2):118-25.

41. Pirro M, Vaudo G, Lupattelli G, Pasqualini L, Mannarino MR, Schillaci G, et al. On-treatment C-reactive protein and HDL cholesterol levels in patients at intermediate cardiovascular risk: impact on carotid intima-media thickness. Life Sci. 2013;93(8):338-43.

42. Gruszfeld D, Weber M, Nowakowska-Rysz M, Janas R, Kozlik-Feldmann R, Xhonneux $A$, et al. Protein intake in infancy and carotid intima media thickness at $5 \hat{A}$ years-a secondary analysis from a randomized trial. Ann Nutr Metab. 2015;66(1):51-9.

43. Klop B, van de Geijn GJ, Bovenberg SA, van der Meulen N, Elte JW, Birnie E, et al. Erythrocyte-bound apolipoprotein B in relation to atherosclerosis, serum lipids and ABO blood group. PLoS One. 2013;8(9), e75573.

44. Calmarza P, Trejo JM, Lapresta C, FernÃ indez M, LÃ $\tilde{A}^{3}$ ez P. Different apolipoprotein $\mathrm{E}$ polymorphisms are not associated with different carotid intima-media thickness values in a sample of Spanish general population. International Cardivascular Research Journal. 2015;9(2):83-8.

45. Kesse-Guyot E, Vergnaud AC, Fezeu L, Zureik M, Blacher J, PÃ@neau S, et al. Associations between dietary patterns and arterial stiffness, carotid artery intima-media thickness and atherosclerosis. European Journal of Cardiovascular Prevention and Rehabilitation. 2010;17:718-24.

46. ViÅjkoviÄキ K, Rutherford GW, Sudario G, Stemberger L, Brni $̈ \neq$ Z, Begovac J. Ultrasound measurements of carotid intima-media thickness and plaque in HIV-infected patients on the Mediterranean diet. Croat Med J. 2013:54(4):330-8.

47. Fang N, Han W, Gong D, Zou C, Fan Y. Atorvastatin treatment for carotid intima-media thickness in Chinese patients with type 2 diabetes: a metaanalysis. Medicine. 2015;94(44), e1920. doi:10.1097/MD.0000000000001920.

48. Yokoi $H$, Nohara $R$, Daida $H$, Hata M, Kaku K, Kawamori $R$, et al. Change in carotid intima-media thickness in a high-risk group of patients by intensive lipid-lowering therapy with rosuvastatin: subanalysis of the JART study. Int Heart J. 2014;55(2):146-52.

49. Anderssen SA, Hjelstuen AK, Hjermann I, Bjerkan K, Holme I. Fluvastatin and lifestyle modification for reduction of carotid intima-media thickness and left ventricular mass progression in drug-treated hypertensives. Atherosclerosis. 2005;178(2):387-97.

50. WaluÅs-Miarka M, Wojciechowska W, Miarka P, Kloch-BadeÅ,ek M, WoÅniakiewicz E, Czarnecka D, et al. Intima-media thickness correlates with features of metabolic syndrome in young people with a clinical diagnosis of familial hypercholesterolaemia. Kardiol Pol. 2013;71(6):566-72.

51. Safarova MS, Trukhacheva EP, Ezhov MV, Afanasâ $€^{\mathrm{TM}}$ eva Ol, Afanasâ€ ${ }^{\mathrm{TM}}$ eva MI, Tripotenâ $€^{\mathrm{TM}} \mathrm{Ml}$, et al. Pleiotropic effects of nicotinic acid therapy in men with coronary heart disease and elevated lipoprotein(a) levels. Kardiologiia 2011;51(5):9-16.

52. Bos S, Duvekot MH, Touw-Blommesteijn AC, Verhoeven AJ, Mulder MT, Watts GF, et al. Lipoprotein (a) levels are not associated with carotid plaques and carotid intima media thickness in statin-treated patients with familial hypercholesterolemia. Atherosclerosis. 2015;242(1):226-9.

53. Mostaza JM, Lahoz C, Salinero-Fort MA, de Burgos-Lunar C, Laguna F, Estirado $E_{1}$ et al. Carotid atherosclerosis severity in relation to glycemic status: a crosssectional population study. Atherosclerosis. 2015;242(2):377-82.
54. Tropeano Al, Boutouyrie P, Katsahian S, Laloux B, Laurent S. Glucose level is a major determinant of carotid intima-media thickness in patients with hypertension and hyperglycemia. J Hypertens. 2004;22(11):2153-60.

55. Kim JH, Kim SY, Jung ES, Jung SW, Koo JS, Kim JH, et al. Carotid intima-media thickness is increased not only in non-alcoholic fatty liver disease patients but also in alcoholic fatty liver patients. Digestion. 2011;84(2):149-55.

56. Kalra L, Iveson E, Rambaran C, Sherwood R, Chowienczyk P, Ritter J, et al. An international matched cohort study of the contribution of metabolic impairments to subclinical atherosclerosis in United Kingdom and Jamaican African-Caribbeans. Atherosclerosis. 2008;199(1):95-101.

57. Sanches PL, Mello MT, Fonseca FA, Elias N, Piano AD, Carnier J, et al. Insulin resistance can impair reduction on carotid intima-media thickness in obese adolescents. Arq Bras Cardiol. 2012;99(4):892-8

58. Shimizu Y, Nakazato M, Sato S, Koyamatsu J, Yamanashi H, Nagayoshi M, et al. Association between hemoglobin A1C and carotid atherosclerosis in rural community-dwelling elderly Japanese men. J Physiol Anthropol. 2015; 34(1):16.

59. Kim HN, Kim SH, Eun YM, Song SW. Obesity with metabolic abnormality is associated with the presence of carotid atherosclerosis in Korean men: a cross-sectional study. Diabetol Metab Syndr. 2015;7:68. doi:10.1186/s13098015-0063-y.eCollection2015.

60. Lorenz MW, Price JF, Robertson C, Bots ML, Polak JF, Poppert H, et al. Carotid intima media thickness progression and risk of vascular events in people with diabetes: results from the PROG-IMT Collaboration. Diabetes Care. 2015 Jul 15. [Epub ahead of print].

61. Kim SH, Lee SJ, Kang ES, Kang S, Hur KY, Lee HJ, et al. Effects of lifestyle modification on metabolic parameters and carotid intimamediathickness in patients with type 2 diabetes mellitus. Metabolism. 2006:55(8):1053-9.

62. Shimizu Y, Sato S, Koyamatsu J, Yamanashi H, Tamai M, Kadota K, et al. Subclinical carotid atherosclerosis and hyperuricemia in relation to renal impairment in a rural Japanese population: the Nagasaki Islands study. Atherosclerosis. 2014:233(2):525-9.

63. Lear SA, Humphries KH, Kohli S, Frohlich JJ, Birmingham CL, Mancini GB. Visceral adipose tissue, a potential risk factor for carotid atherosclerosis: results of the Multicultural Community Health Assessment Trial (M-CHAT). Stroke. 2007;38(9):2422-9.

64. Lee MJ, Shin DH, Kim SJ, Oh HJ, Yoo DE, Kim JK, et al. Visceral fat thickness is associated with carotid atherosclerosis in peritoneal dialysis patients. Obesity (Silver Spring). 2012;20(6):1301-7.

65. Hartiala O, Magnussen CG, Bucci M, Kajander S, Knuuti J, Ukkonen H, et al. Coronary heart disease risk factors, coronary artery calcification and epicardial fat volume in the Young Finns Study. Eur Heart J Cardiovasc Imaging. 2015 Apr 20. [Epub ahead of print].

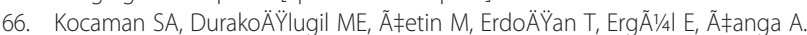
The independent relationship of epicardial adipose tissue with carotid intima-media thickness and endothelial functions: the association of pulse wave velocity with the active facilitated arterial conduction concept. Blood Press Monit. 2013;18(2):85-93

67. Yun $\mathrm{CH}$, Longenecker CT, Chang HR, Mok GS, Sun JY, Liu CC, et al. The association among peri-aortic root adipose tissue, metabolic derangements and burden ofatherosclerosis in asymptomatic population. J Cardiovasc Comput Tomogr. 2015. doi:10.1016/j.jcct.2015.10.002 [Epub ahead of print].

68. Petit JM, Guiu B, Masson D, Duvillard L, Jooste V, Buffier P, et al. Specifically PNPLA3-mediated accumulation of liver fat in obese patients with type 2 diabetes. J Clin Endocrinol Metab. 2010;95(12):E430-6.

69. Laing ST, Smulevitz B, Vatcheva KP, Rahbar MH, Reininger B, McPherson DD, et al. Subclinical atherosclerosis and obesity phenotypes among Mexican Americans. J Am Heart Assoc. 2015:4(3), e001540. doi:10.1161/JAHA.114. 001540

70. Barcellos CR, Lage SH, Rocha MP, Hayashida SA, Baracat EC, Romano A, et al. Polycystic ovary syndrome and obesity do not affect vascular parameters related to early atherosclerosis in young women without glucose metabolism disturbances, arterial hypertension and severe abnormalities of lipid profile. Gynecol Endocrinol. 2013:29(4):370-4.

71. Megias-Rangil I, Merino J, Ferr Ã@ R, Plana N, Heras M, CabrÃ@ A, et al. Subclinical atherosclerosis determinants in morbid obesity. Nutr Metab Cardiovasc Dis. 2014;24(9):963-8.

72. Oni ET, Agatston AS, Blaha MJ, Fialkow J, Cury R, Sposito A, et al. A systematic review: burden and severity of subclinical cardiovascular disease 
among those with nonalcoholic fatty liver; should we care? Atherosclerosis. 2013;230(2):258-67

73. Cai J, Zhang S, Huang W. Association between nonalcoholic fatty liver disease and carotid atherosclerosis: a meta-analysis. Int J Clin Exp Med. 2015;8(5):7673-8.

74. DemircioÄ̈̈lu F, KoÃßyï̈̈̈it A, Arslan N, CakmakÃß̧i H, Hizli S, Sedat AT. Intimamedia thickness of carotid artery and susceptibility to atherosclerosis in obese children with nonalcoholic fatty liver disease. J Pediatr Gastroenterol Nutr. 2008:47(1):68-75

75. Qu BG, Wang H, Liu YX, Jia YG, Su JL, Wang ZD, et al. Causes of thickening of carotid intima-media thickness in patients with alcoholic liver disease: a prospective observational study. Medicine. 2015;94(28), e1087. doi:10.1097/ MD.0000000000001087.

76. Sert A, Aypar E, Pirgon O, Yilmaz H, Odabas D, Tolu I. Left ventricular function by echocardiography, tissue Doppler imaging, and carotid intimamedia thickness in obese adolescents with nonalcoholic fatty liver disease. Am J Cardiol. 2013;112(3):436-43.

77. Wang CC, Lin SK, Tseng YF, Hsu CS, Tseng TC, Lin HH, et al. Elevation of serum aminotransferase activity increases risk of carotid atherosclerosis in patients with non-alcoholic fatty liver disease. J Gastroenterol Hepatol. 2009; 24(8):1411-6.

78. Arinc H, Sarli B, Baktir AO, Saglam H, Demirci E, Dogan Y, et al. Serum gamma glutamyl transferase and alanine transaminase concentrations predict endothelial dysfunction in patients with non-alcoholic steatohepatitis. Ups J Med Sci. 2013;118(4):228-34.

79. Luque-RamÃrez M, Mendieta-Azcona C, Alvarez-Blasco F, Escobar-Morreale HF. Androgen excess is associated with the increased carotid intima-media thickness observed in young women with polycystic ovary syndrome. Hum Reprod. 2007;22(12):3197-203.

80. Rampersaud E, Bielak LF, Parsa A, Shen H, Post W, Ryan KA, et al. The association of coronary artery calcification and carotid artery intima-media thickness with distinct, traditional coronary artery disease risk factors in asymptomatic adults. Am J Epidemiol. 2008;168(9):1016-23.

81. Sabater-Lleal M, MÃalarstig A, Folkersen L, Soler Artigas M, Baldassarre $D$, Kavousi $M$, et al. Common genetic determinants of lung function, subclinical atherosclerosis and risk of coronary artery disease. PLoS One. 2014;9(8), e104082. doi:10.1371/journal.pone.0104082. eCollection2014.

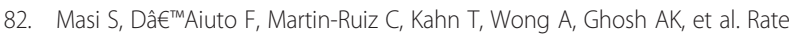
of telomere shortening and cardiovascular damage: a longitudinal study in the 1946 British Birth Cohort. Eur Heart J. 2014;35(46):3296-303.

83. Samani NJ, Raitakari OT, SipilÃ̊ K, Tobin MD, Schunkert H, Juonala M, et al. Coronary artery disease-associated locus on chromosome 9p21 and early markers of atherosclerosis. Arterioscler Thromb Vasc Biol. 2008:28(9):1679-83.

84. Ragab SM, Safan MA, Badr EA, Ebeid OM. Haptoglobin genotypes polymorphism as a risk factor for subclinical atherosclerosis in betathalassemia major children; a single center Egyptian study. Hematology 2014 Dec 26. [Epub ahead of print].

85. Strawbridge RJ, Deleskog A, McLeod O, Folkersen L, Kavousi M, Gertow K, et al. A serum 25 -hydroxyvitamin D concentration-associated genetic variant in DHCR7 interacts with type 2 diabetes status to influence subclinical atherosclerosis (measured by carotid intima-media thickness). Diabetologia. 2014;57(6):1159-72.

86. Cunnington MS, Mayosi BM, Hall DH, Avery PJ, Farrall M, Vickers MA, et al. Novel genetic variants linked to coronary artery disease by genome-wide association are not associated with carotid artery intima-media thickness or intermediate risk phenotypes. Atherosclerosis. 2009;203(1):41-4.

87. de las Fuentes L, Gu CC, Mathews SJ, Reagan JL, Ruthmann NP, Waggoner $A D$, et al. Osteopontin promoter polymorphism is associated with increased carotid intima-media thickness. J Am Soc Echocardiogr. 2008;21(8):954-60.

88. Sinha PK, Santr G, De D, Sah A, Biswas K, Bhattachary P, et al. Carotid intimamedia thickness in type 2 diabetes mellitus patients with cardiac autonomic neuropathy. J Assoc Physicians India. 2012;60:14-8.

89. Ciftci FC, Caliskan M, Ciftci O, Gullu H, Uckuyu A, Toprak E, et al. Impaired coronary microvascular function and increased intima-media thickness in preeclampsia. J Am Soc Hypertens. 2014;8(11):820-6.

90. Ikeda N, Gupta A, Dey N, Bose S, Shafique S, Arak T, et al. Improved correlation between carotid and coronary atherosclerosis SYNTAX score using automated ultrasound carotid bulb plaque IMT measurement. Ultrasound Med Biol. 2015;41(5):1247-62.
91. Melo X, Santa-Clara H, Santos DA, Pimenta NM, Minderico CS, Fernhall B, et al. Independent association of muscular strength and carotid intimamedia thickness in children. Int J Sports Med. 2015;36(8):624-30.

92. Pacifico L, Anania C, Martino F, Cantisani V, Pascone R, Marcantonio A, et al. Functional and morphological vascular changes in pediatric nonalcoholic fatty liver disease. Hepatology. 2010;52(5):1643-51.

93. Liu YL, Szklo M, Davidson KW, Bathon JM, Giles JT. Psychosocial comorbidities are differentially associated with subclinical atherosclerosis in rheumatoid arthritis: Comparison with MESA. Arthritis Care Res (Hoboken). 2015. doi:10.1002/acr.22635 [Epub ahead of print].

94. Park YB, Ahn CW, Choi HK, Lee SH, In BH, Lee HC, et al. Atherosclerosis in rheumatoid arthritis: morphologic evidence obtained by carotid ultrasound. Arthritis Rheum. 2002:46(7):1714-9.

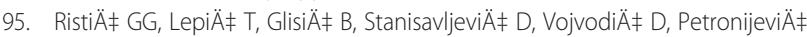
$M$, et al. Rheumatoid arthritis is an independent risk factor for increased carotid intima-media thickness: impact of anti-inflammatory treatment. Rheumatology (Oxford). 2010:49(6):1076-81.

96. Carotti M, Salaffi F, Mangiacotti M, Cerioni A, Giuseppetti GM, Grassi W. Atherosclerosis in rheumatoid arthritis: the role of high-resolution B mode ultrasound in the measurement of the arterial intima-media thickness. Reumatismo. 2007:59(1):38-49.

97. Detrano R, Scott Jr WW, Kronmal RA, Bathon JM. Coronary arterial calcification in rheumatoid arthritis: comparison with the Multi-Ethnic Study of Atherosclerosis. Arthritis Res Ther. 2009;11(2):R36. doi:10.1186/ar2641. Epub 2009 Mar 10

98. Giles JT, Szklo M, Post W, Petri M, Blumenthal RS, Lam G, et al. Subclinical atherosclerosis in young patients with rheumatoid arthritis and low disease activity. Reumatismo. 2005;57(1):16-21.

99. Peters MJ, van Halm VP, Nurmohamed MT, Damoiseaux J, Tervaert JW, Twisk JW, et al. Relations between autoantibodies against oxidized low-density lipoprotein, inflammation, subclinical atherosclerosis, and cardiovascular disease in rheumatoid arthritis. J Rheumatol. 2008;35(8): 1495-9.

100. Profumo E, Di Franco M, Buttari B, Masella R, Filesi C, Tosti ME, et al. Biomarkers of subclinical atherosclerosis in patients with autoimmune disorders. Mediators Inflamm. 2012;2012:503942. doi:10.1155/2012/503942. Epub 2012 Feb 22

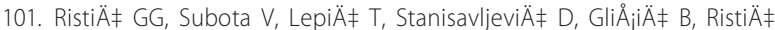
$A D$, et al. Subclinical atherosclerosis in patients with rheumatoid arthritis and low cardiovascular risk: the role of von Willebrand factor activity.

PLoS One. 2015;10(8), e0130462. doi:10.1371/journal.pone.0130462. eCollection2015.

102. Troelsen LN, Garred P, Christiansen B, Torp-Pedersen C, Christensen IJ, Narvestad $E_{\text {, et }}$ al. Double role of mannose-binding lectin in relation to carotid intima-media thickness in patients with rheumatoid arthritis. Mol Immunol. 2010;47(4):713-38.

103. Lo Gullo A, Mandraffino G, Bagnato G, Aragona CO, Imbalzano E, Dâ

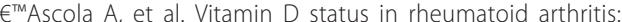
inflammation, arterial stiffness and circulating progenitor cell number PLOS One. 2015;10(8), e0134602. doi:10.1371/journal.pone.0134602. eCollection2015.

104. Marder W, Khalatbari S, Myles JD, Hench R, Yalavarthi S, Lustig S, et al. Interleukin 17 as a novel predictor of vascular function in rheumatoid arthritis. Ann Rheum Dis. 2011;70(9):1550-5.

105. Shaharyar S, Warraich H, McEvoy JW, Oni E, Ali SS, Karim A, et al. Subclinical cardiovascular disease in plaque psoriasis: association or causal link? Atherosclerosis. 2014;232(1):72-8

106. Troitzsch P, Paulista Markus MR, DÃ Irr M, Felix SB, JÃ¹/4nger M, Schminke U, et al. Psoriasis is associated with increased intima-media thickness-the Study of Health in Pomerania (SHIP). Atherosclerosis. 2012;225(2):486-90.

107. Eder L, Jayakar J, Shanmugarajah S, Thavaneswaran A, Pereira D, Chandran V, et al. The burden of carotid artery plaques is higher in patients with psoriatic arthritis compared with those with psoriasis alone. Ann Rheum Dis. 2013;72(5):715-20.

108. Ilisson J, Zagura M, Zilmer K, Salum E, Heilman K, Piir A, et al. Increased carotid artery intima-media thickness and myeloperoxidase level in children with newly diagnosed juvenile idiopathic arthritis. Arthritis Res Ther. 2015; 17:180. doi:10.1186/s13075-015-0699-x.

109. Ahmad HM, Sarhan EM, Komber U. Higher circulating levels of OxLDL \% of LDL are associated with subclinical atherosclerosis in female patients with systemic lupus erythematosus. Rheumatol Int. 2014;34(5):617-23. 
110. Merashli M, Ster IC, Ames PR. Subclinical atherosclerosis in Behcetâ $€^{T M} S$ disease: a systematic review and meta-analysis. Semin Arthritis Rheum. 2015. doi:10.1016/j.semarthrit.2015.06.018 [Epub ahead of print].

111. Gravani F, Papadaki I, Antypa E, Nezos A, Masselou K, loakeimidis D, et al. Subclinical atherosclerosis and impaired bone health in patients with primary SjÃ gren syndrome: prevalence, clinical and laboratory associations. Arthritis Res Ther. 2015;17(1):99. doi:10.1186/s13075015-0613-6.

112. Zardi EM, Sambataro G, Basta F, Margiotta DP, Afeltra AM. Subclinical carotid atherosclerosis in elderly patients with primary SjÃAgren syndrome: a duplex Doppler sonographic study. Int J Immunopathol Pharmacol. 2014;27(4):645-51.

113. Topaloglu O, Gokay F, Kucukler K, Burnik FS, Mete T, Yavuz HC, et al. Is autoimmune thyroiditis a risk factor for early atherosclerosis in premenopausal women even if in euthyroid status? Endocrine. 2013; 44(1):145-51.

114. Evelein AM, Visseren FL, van der Ent CK, Grobbee DE, Uiterwaal CS. Allergies are associated with arterial changes in young children. Eur J Prev Cardiol. 2014 Oct 9. [Epub ahead of print].

115. Ahmed HM, Youssef M, Mosaad YM. Antibodies against oxidized lowdensity lipoprotein are associated with subclinical atherosclerosis in recent-onset rheumatoid arthritis. Clin Rheumatol. 2010;29(11):1237-43.

116. Osorio JM, Ferreyra C, PÃ@rez A, Moreno JM, Osuna A. Prediabetic States, subclinical atheromatosis, and oxidative stress in renal transplant patients. Transplant Proc. 2009;41(6):2148-50.

117. Santl Letonja M, Letonja M, IkolajeviÄł-Starcevï̈ł JN, Petrovic D. Association of manganese superoxide dismutase and glutathione $\mathrm{S}$ transferases genotypes with carotid atherosclerosis in patients with diabetes mellitus type 2. Int Angiol. 2012;31(1):33-41.

118. Loimaala A, Rontu R, Vuori I, Mercuri M, LehtimÃaki T, Nenonen A, et al. Blood leukocyte count is a risk factor for intima-media thickening and subclinical carotid atherosclerosis in middle-aged men. Atherosclerosis. 2006;188(2):363-9.

119. Cingoz F, lyisoy A, Demirkol S, Sahin MA, Balta S, Celik T, et al. Carotid intima-media thickness in patients with slow coronary flow and its association with neutrophil-to-lymphocyte ratio: a preliminary report. Clin Appl Thromb Hemost. 2014;20(4):393-9.

120. Schoffelen AF, de Groot E, Tempelman HA, Visseren FL, Hoepelman Al, Barth RE. Carotid intima media thickness in mainly female HIV-infected subjects in rural South Africa: association with cardiovascular but not HIV-related factors. Clin Infect Dis. 2015 Jul 27. [Epub ahead of print].

121. Portilla J, Moreno-PÃ@rez O, Serna-Candel C, EscoÃn C, Alfayate R, Reus S, et al. Vitamin D insufficiency and subclinical atherosclerosis in non-diabetic males living with HIV. J Int AIDS Soc. 2014;17:18945. doi:10.7448/IAS.17.1. 18945.eCollection2014.

122. Qu B, Su J, Wang Z, Wang $Y$, Han $X$, Wang $H$, et al. Effect of $H$. Pylori infection on cytokine profiles and oxidative balance in subjects with chronic alcohol ingestion. PLOS One. 2015;10(6), e0129352.

123. Desvarieux M, Schwahn C, VÃ $\mid$ lzke H, Demmer RT, LÃ/4demann J, Kessler C, et al. Gender differences in the releriodontal disease, tooth loss, and atherosclerosis. Stroke. 2004;35(9):2029-35.

124. Hintsanen M, Elovainio M, Puttonen S, KivimÃaki M, Lehtimãaki T, KÃ ahÃ nen $\mathrm{M}$, et al. Val/Met polymorphism of the COMT gene moderates the association between jobstrain and early atherosclerosis in young men. J Occup Environ Med. 2008;50(6):649-57.

125. Hintsa T, Kivimãaki M, Elovainio M, Vahtera J, Hintsanen M, Viikari J, et al. Is the association between job strain and carotid intima-media thickness attributable to pre-employmentenvironmental and dispositional factors? The cardiovasclar Risk in Young Finns Study. Occup Environ Med. 2008;65: 676-82.

126. Hintsanen M, KivimÃaki M, Elovainio M, Pulkki-RÃ $¥$ back $L$, Keskivaara $P$, Juonala $\mathrm{M}$, et al. Job strain and early atherosclerosis:the Cardiovascular Risk in Young Finns study. Psychosom Med. 2005;67(5):740-7.

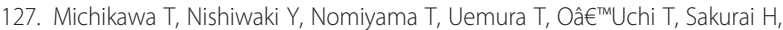
et al. Job strain and arteriosclerosis in Three different types of arteries among male Japanese factory workers. Scand J Work Environ Health. 2008;34(1):48-54.

128. Camelo LV, Giatti L, Chor D, Griep RH, BenseÃ \pm or IM, Santos IS, et al. Associations of life course socioeconomic position and job stress with carotid intima-media thickness. The Brazilian Longitudinal Study of Adult Health (ELSA-Brasil). Soc Sci Med. 2015;141:91-9.
129. Puttonen S, KivimÃaki M, Elovainio M, Pulkki-RÃ̋̈back L, Hintsanen M, Vahtera J, et al. Shift work in young adults and carotid artery intima- media thickness: The cardiovascular Risk in Young Finnsstudy. Atherosclerosis. 2009;205(2):608-13.

130. Rosvall M, Ostergren PO, Hedblad B, Isacsson SO, Janzon L, Berglund G. Work-related psychosocial factors and carotid atherosclerosis. Int J Epidemiol. 2002;31(6):1169-78.

131. Juonala M, Voipio A, Pahkala K, Viikari JS, Mikkilãa V, KÃahÃ nnen M, et al. Childhood $25-\mathrm{OH}$ vitamin D levels and carotid intima-media thickness in adulthood: the cardiovascular risk in young Finns study. J Clin Endocrinol Metab. 2015;100(4):1469-76.

132. Robinson AB, Tangpricha V, Yow E, Gurion R, Schanberg LE, McComsey GA, et al. Vitamin $D$ status is a determinant of atorvastatin effect on carotid intima medial thickening progression rate in children with lupus: an Atherosclerosis Prevention in Pediatric Lupus Erythematosus (APPLE) substudy. Lupus Sci Med. 2014;1(1): e000037. doi:10.1136/lupus-2014-000037. eCollection 2014.

133. Baker CP, Kulkarni B, Radhakrishna KV, Charyulu MS, Gregson J, Matsuzaki M, et al. Is the Association between Vitamin D and Cardiovascular Disease Risk Confounded by Obesity? Evidence from the Andhra Pradesh Children and Parents Study (APCAPS). PLoS One. 2015;10(6), e0129468. doi:10.1371/journal.pone.0129468eCollection2015.

134. Deleskog A, Piksasova O, Silveira A, Gertow K, Baldassarre D, Veglia F, et al. Serum 25-hydroxyvitamin concentration in subclinical carotid atherosclerosis. Arterioscler Thromb Vasc Biol. 2013;33(11):2633-8. doi:10.1161/ATVBAHA.113.301593. Epub 2013 Sep 26.

135. Reis JP, von MÃ/4hlen D, Michos ED, Miller 3rd ER, Appel LJ, Araneta MR, et al. Serum vitamin D, parathyroid hormone levels, and carotid atherosclerosis. Atherosclerosis. 2009;207(2):585-90.

136. Kamycheva E, Johnsen SH, Wilsgaard T, Jorde R, Mathiesen EB. Evaluation of serum 25-hydroxyvitamin $D$ as a predictor of carotid intima-media thickness and carotid total plaque area in nonsmokers: the troms $\tilde{A}$, study. Int J Endocrinol. 2013;2013:305141. doi:10.1155/2013/305141. Epub 2013 Nov 20.

137. SÃ 9 der PO, Meurman JH, Jogestrand T, Nowak J, SÃ der B. Matrix metalloproteinase-9 and tissue inhibitor of matrix metalloproteinase-1 in blood as markers for early atherosclerosis in subjects with chronic periodontitis. J Periodontal Res. 2009;44(4):452-8.

138. Abdelnaseer M, Elfayomi N, Esmail EH, Kamal MM, Hamdy A, Samie RM, et al. Relationship between matrix metalloproteinase- 9 and common carotid artery intima media thickness. Neurol Sci. 2015 Aug 30. [Epub ahead of print].

139. Orbe J, Montero I, RodrÃguez JA, Beloqui O, Roncal C, PÃ iramo JA. Independent association of matrix metalloproteinase-10, cardiovascular risk factors and subclinical atherosclerosis. J Thromb Haemost. 2007:5(1):91-7.

140. Kong $X$, Jia X, Wei $Y$, Cui M, Wang Z, Tang L, et al. Association between microalbuminuria and subclinical atherosclerosis evaluated by carotid artery intima-media in elderly patients with normal renal function. BMC Nephrol. 2012;13:37. doi:10.1186/1471-2369-13-37.

141. Aykas F, Solak Y, Erden A, Bulut K, Dogan S, Sarli B, et al. Persistence of cardiovascular risk factors in women with previous preeclampsia: a longterm follow-up study. J Investig Med. 2015;63:641-5.

142. Breton CV, Wang X, Mack WJ, Berhane K, Lopez M, Islam TS, et al. Childhood air pollutant exposure and carotid artery intima-media thickness in young adults. Circulation. 2012;126:1614-20.

143. Shimizu M, Furusyo N, Mitsumoto F, Takayama K, Ura K, Hiramine S, et al. Subclinical carotid atherosclerosis and triglycerides predict the incidence of chronic kidney disease in the Japanese general population: results from the Kyushu and Okinawa Population Study (KOPS). Atherosclerosis. 2015;238(2):207-12.

144. Binay C, Simsek E, Y $\ddot{A} \pm 1 d \ddot{A} \pm r \ddot{A} \pm m$ A, Kosger P, Demiral M, K $\ddot{A} \pm \mid \ddot{A} \pm \tilde{A} \S Z$. Growth hormone and the risk of atherosclerosis in growth hormonedeficient children. Growth Horm IGF Res. 2015. doi:10.1016/j.ghir.2015. 08.005 [Epub ahead of print].

145. Gullu H, Caliskan M, Caliskan Z, Unler GK, Ermisler E, Ciftci O, et al. Coronary microvascular function, peripheral endothelial function and carotid IMT in beta-thalassemia minor. Thromb Res. 2013;131(6):e247-52.

146. Wildman RP, Schott LL, Brockwell S, Kuller LH, Sutton-Tyrrell K. A dietary and exercise intervention slows menopause-associated progression of subclinica atherosclerosis as measured by intima-media thickness of the carotid arteries. J Am Coll Cardiol. 2004:44(3):579-85.

147. Bossuyt J, Vandekerckhove G, De Backer TL, Van de Velde S, Azermai M, Stevens AM, et al. Vascular dysregulation in normal-tension glaucoma is not affected by structure and function of the microcirculation or macrocirculation at rest: a case-control study. Medicine (Baltimore). 2015; 94(2), e425. doi:10.1097/MD.0000000000000425. 